\title{
A NEW AND EFFECTIVE DECISION-MAKING PLATFORM FOR BATTERY SELECTION AIMING TO ACHIEVE STANDARDIZATION IN MINING INDUSTRY
}

\author{
César Catizanea , Edmundo Neto ${ }^{a}$, Estevão Gomes ${ }^{a}$, Lilian Lefol Nani Guarieiroa, \\ Rodrigo Coelho ${ }^{a}$, Alexandre Alves da Silva ${ }^{b}$ \\ a, Centro Universitário SENAI CIMATEC, Av. Orlando Gomes 1845, 41.650-010, \\ Salvador, BA, Brasil \\ b VALE S.A., Estratégia e Tecnologia, Praia de Botafogo, 186, 22250-145, Rio de \\ Janeiro, RJ, Brasil
}

\begin{abstract}
Nowadays, there is an increasingly concern about finding solutions to achieve environmental sustainability. The use of electric vehicles (EVs) appears as an option. The mining industry is in this direction, however, problems related to costs and circular economy hinder the development. The latter is especially complicated since there is a lack of standardization. In this work, a decision-making helping tool for batteries selection for electrification of heavy-duty vehicles was developed, aiming to provide means for standardization. It works using a Multi-Criteria Decision-Making (MCDM) method called WASPAS. As result, a customized rank of batteries according to the preferences is shown. Then, the user must be able to choose the best battery. The platform is highly effective and can provide a unique standardization opportunity.
\end{abstract}

Keywords: Electrification; Batteries; Multi-Criteria Decision-Making; Electric Vehicles.

\section{UMA NOVA E EFICIENTE PLATAFORMA DE AUXÍLIO A TOMADA DE DECISÃO PARA SELEÇÃO DE BATERIAS VISANDO ALCANÇAR A PADRONIZAÇÃO NA INDUSTRIA DE MINERAÇÃO}

Resumo: Atualmente, há uma preocupação cada vez maior em encontrar soluções para alcançar a sustentabilidade. O uso de veículos elétricos (EVs) surge como uma opção. A indústria de mineração também está nessa direção, porém problemas de custos e economia circular dificultam o desenvolvimento. Este último é complicado, já que há uma falta de padronização. Neste trabalho, uma ferramenta de auxílio à tomada de decisão na seleção de baterias para eletrificação de veículos pesados, foi desenvolvida, visando fornecer meios para padronização. Um método de tomada de decisão multicritério (MCDM) chamado WASPAS foi usado como motor. Como resultado, um rank de baterias é exibido de acordo com as preferências do usuário. $A$ plataforma é altamente eficaz e pode fornecer uma oportunidade para a padronização.

Palavras-chave: Electrification; Batteries; Multi-Criteria Decision-Making; Electric Vehicles. 


\section{INTRODUCTION}

The society is increasingly concerned about finding solutions to achieve the environmental sustainability and socio-economic wealth standards for upcoming generations [1]. In this context, solutions such as use of cleaner fuels or EVs are being universally used. In addition, increasing the usage of EVs can enable enormous benefits related to public health since it reduces the formation of smog from gasoline or diesel-fueled vehicles.

The mining industry is following the same trend, but it is facing some major problems. Vendor lock-in is one of such issues. Each vehicle has its own type of battery and when the user needs to exchange it or buy a new one, there is only one option. This problem also happens with phones and other electronics [2]. Thus, the supplier has potential to control the market and can impose high prices for the product.

Another problem is related to the creation of a battery circular economy. Since there are many different battery chemistries and topologies available, battery second life usage becomes difficult. It also leads to an expensive recycling process, making it more difficult or even economically unviable [3], and absence of recycling process standards. Lastly, there is the high production cost problem, in which the smaller the production site, more expensive the final product will be [4].

The resolution of these problems comes up against the great difficulty of finding accurate information and specifications related to the available battery systems. One way to solve these problems may be to standardize batteries, in terms of chemistry, geometry and disposition. This standardization can provide a means to close the battery supply chain loop, thus facilitating the use in second life and recycling process. Therefore, we propose a decision-making helping tool to achieve battery standardization, with more complete specifications taking into consideration the user's preferences.

The main objective of this work is the development of a decision-making support platform, capable of cross-referencing the data entered by the user with the created databases to select the most suitable battery for an electrification process. Four data sources are used: EVs and energy storage systems (ESS) markets, scientific articles, patents, and financial and stock markets. As output, a ranking of the best battery options available in the market is delivered. With this platform, it is intended to increase the efficiency of the selection of batteries, reducing costs, avoiding the generation of environmental liabilities, and achieving an internal standardization of batteries. The prototype was named 'BatteryFit platform', which was developed in excel, with potential for further expansion.

\section{METHODOLOGY}

Figure 1 shows the methodology applied on the developed tool. It is based on data research on the battery modules that are studied, carried on different informational sources, and an evaluation of the data gathered. Such evaluation occurs through rating of the battery characteristics found and the implementation of a weight to each of characteristics. These characteristics are listed in Table 1. 
The data research was carried out both manually and automatically, through web scraping and web crawling algorithms created specifically for this work. EVs and ESS market information was used to give the actual data on battery characteristics and their most efficient usage profile. Scientific researches and patents were analyzed to provide an overview of emerging technologies on the field and their applications on the industry, together with further developments on existing technology and on data related to battery energy characteristics gathering.

Figure 1. BatteryFit methodology.

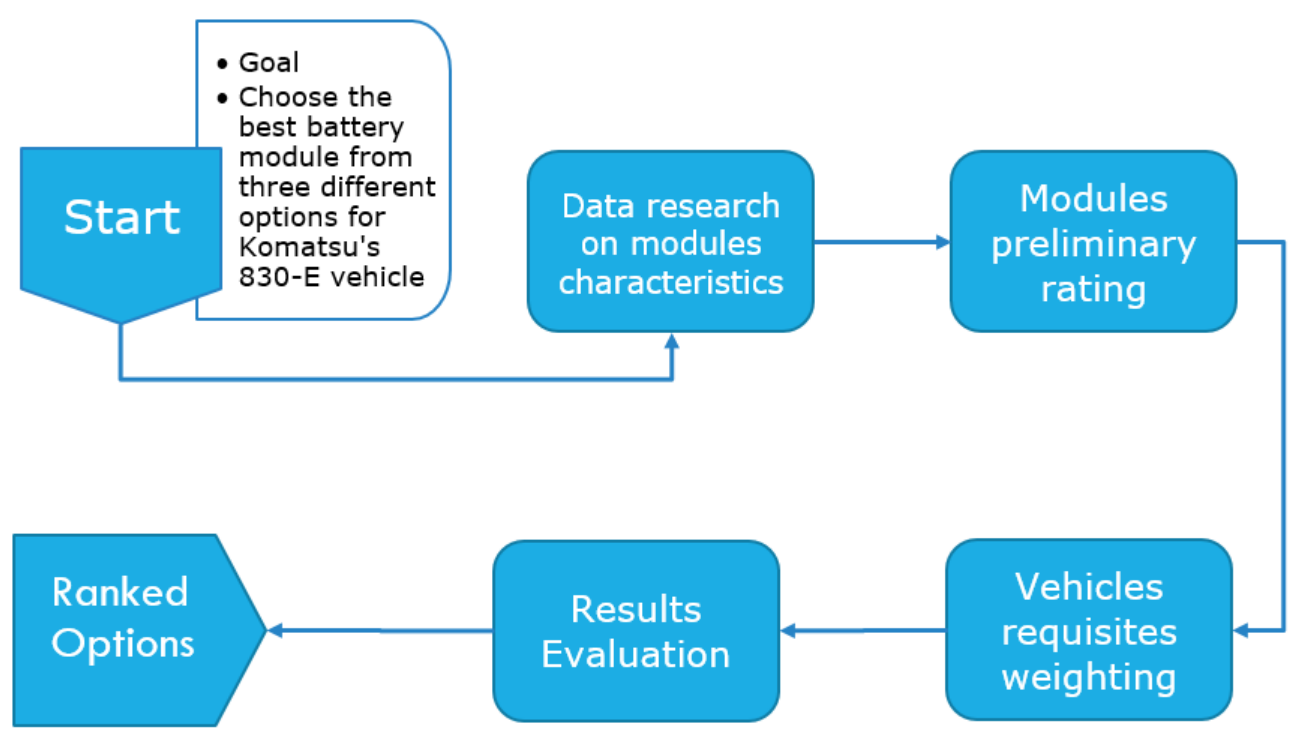

Source: Elaborated by the authors.

Lastly, financial and stocks market provided information on supplier's production capacity and prices. One truck was selected as subject, as well as three lithium-ion modules (Nickel-Manganese-Cobalt (NMC), Lithium-Iron-Phosphate (LFP) and Lithium-Titanate-Oxide (LTO)), from Samsung SDI, Contemporary Amperex Technology Limited (CATL) and Toshiba, respectively. The module level, instead of cell or pack, was chosen due to a more present standard on the market, as well as the presence of modular solutions for batteries becoming more present on the market as a whole [5]. The vehicle chosen was the Komatsu's 830-E, which is an ultra-class haul truck widely applied in open pit mining operations.

The platform uses as a backend algorithm an MCDM method called WASPAS, which is used to define the best battery choice among all possible ones, considering the user inputs and the usage profile (light, medium, or aggressive). This method was selected among others 14 MCDM methods, after testing, observing criteria such as ease of use, method limitations and robustness of results. 
Table 1. Requisites for WASPAS.

WASPAS Requisites

\begin{tabular}{l}
\hline Volumetric Energy Density $\left(\mathrm{Wh} \mathrm{L}^{-1}\right)$ \\
Volumetric Power Density $\left(\mathrm{W} \mathrm{L}^{-1}\right)$ \\
\hline Specific energy $\left(\mathrm{Wh} \mathrm{kg}^{-1}\right)$ \\
Specific power $\left(\mathrm{W} \mathrm{kg}{ }^{-1}\right)$ \\
Minimum charging time (hours) \\
Buying cost $(\$ \mathrm{kWh}-1)$ \\
Operational cost $\left(\$ \mathrm{kWh}^{-1}\right)$ \\
Maintenance Cost $\left(\$ \mathrm{kWh}^{-1}\right)$ \\
Recycling cost $(\$ \mathrm{kWh}-1)$ \\
\hline Accidents security $(\mathrm{Low}$, medium, or high) \\
Charge security $(\mathrm{Low}$, medium, or high) \\
Working temperature Maximum $\left({ }^{\circ} \mathrm{C}\right)$ \\
Working temperature minimum $\left({ }^{\circ} \mathrm{C}\right)$ \\
Life cycles $(\#)$
\end{tabular}

Source: Elaborated by the authors.

\section{RESULTS AND DISCUSSION}

The result is the relative importance of each battery for the given weight profile. From the implementation of the WASPAS method with the data gathered and evaluated for the battery technologies, graphs were built comparing the compatibility of each battery technology for each profile. The results are shown on Figure 2.

Figure 2. Relative importance of each battery chemistry per usage profile.

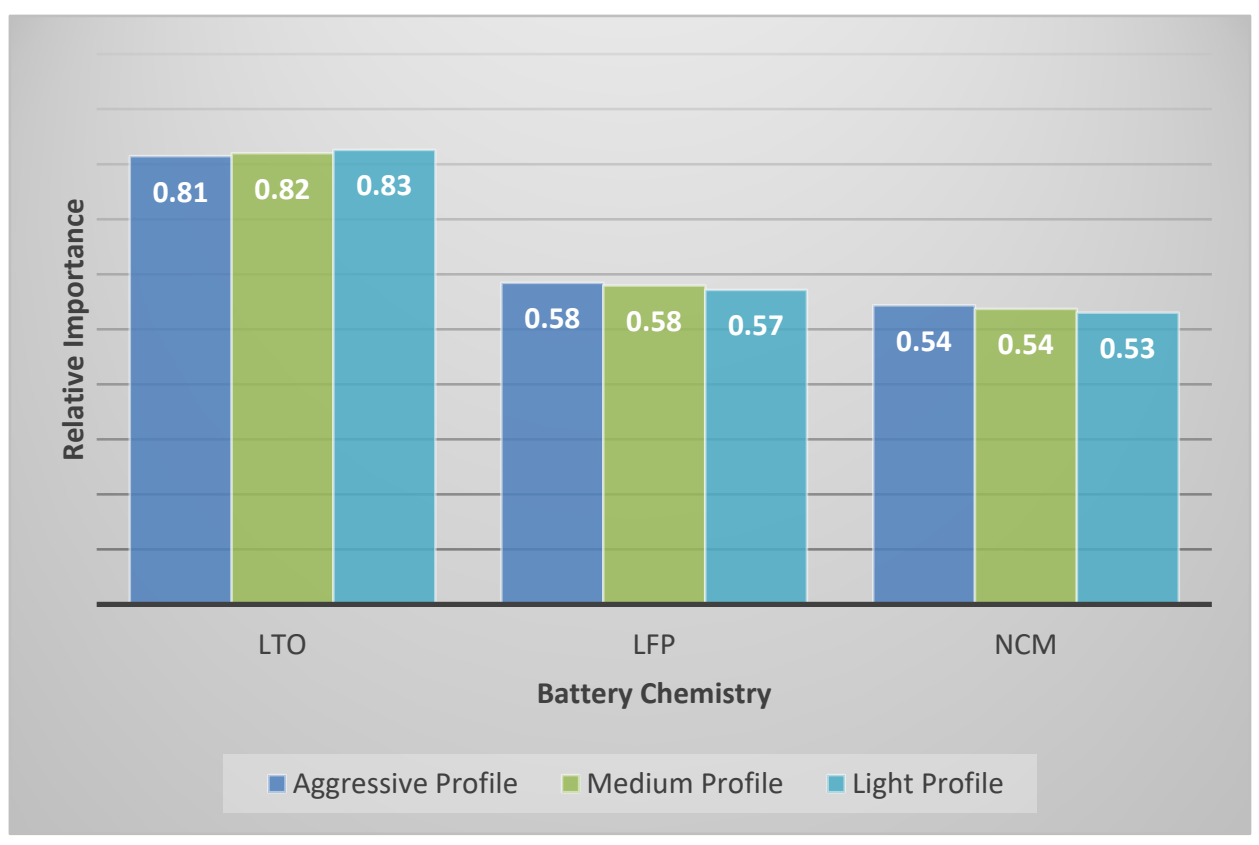

Source: Elaborated by the authors. 
The relative weight for the batteries characteristics was the differentiation between the different profiles in which the batteries were evaluated and were defined through literature study and consultation with specialists. Those profiles are based on characteristics such as vehicle load, cycles of usage (charge-discharge), charging time, and working temperatures. These profiles were nominated as light, medium, and aggressive.

The analysis of Figure 2 allows the observation that there is little difference between the profiles on the way they were implemented, with fluctuations of values being, at most, 1.3 points. This happens due to the existence of only 2 of 14 requisites varying between the different profiles, the energy and power densities characteristics, which do not cause big changes on the overall situation of the technologies. From this, LTO raises as the most compatible battery by a heavy margin amongst the selected batteries. According to the analysis of all data used for the study, this fact arises due to the quantity of requisites in which this battery stands out, which are the charging time, the life cycles of the battery, its security, Operation and Maintenance (O\&M) costs. But this raises a question about the data itself.

The factors that give LTO an advantage comprehend 7 out of the 14 requisites evaluated in total, and 5 of which are using data assumed from literature research. This brings the question of how much the results would change if this data were inaccurately assessed. To try to answer that question and evaluate the data analysis capabilities of the methodology applied, a comparison method was created. It consists of checking the possible fluctuation of values on compatibility of the 2 batteries not selected by the method according to fluctuations on the requisites with estimated values. The results can be seen on Figure 3.

Figure 3. Relative importance variation according to recycling cost requisite values.

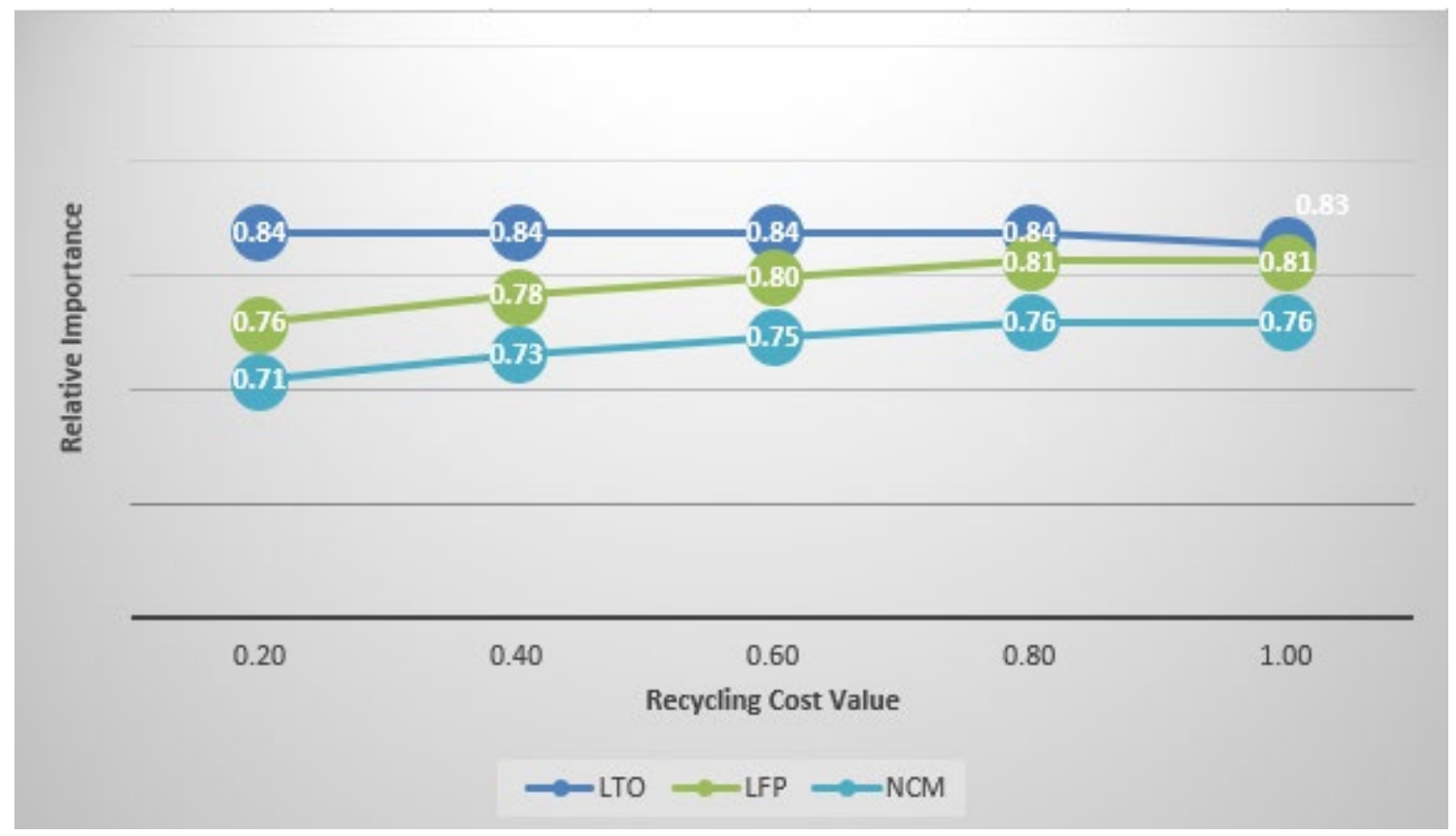

Source: Elaborated by the authors.

These numbers reflect the variation in compatibility related to the changes in values of any of the 5 estimated requisites, when all the other 4 are kept equal and 
constant. From the numbers when all the values are kept equal, LTO still is the chosen technology, even though it now has a much smaller advantage over the other choices.

The LTO technology is the one with the most attendance of the requisites, and thus, has huge advantage over the competition on a few of them, such as life cycle, and security [6]. Still, some reservation must be done where it is due. The NCM chemistry with highest market share - technology studied is the 3:3:3 type (with equal parts of Manganese, Cobalt, and Nickel). However, there are already more modern solutions on the market, with 6:2:2 composition. There are even other chemistries being developed with 8:1:1 type, which will raise even more the energy and power densities delivery capabilities. These new batteries can tip the scales of this analysis, but it is not a certainty, since it can also diminish their thermal stability, compromising its efficiency on safety requisites $[7,8]$.

As for the LFP, the module chosen for this work is not necessarily the best option available, as life-cycle for this chemistry can, theoretically, reach the margin of 7000 cycles, giving it an advantage over NCM and other batteries with higher energy densities. It can also overcome the LTO, reason why it is the most implemented battery chemistry on the truck operations of mining industries, but since no module with such characteristic was found, it was not a part of the study.

Lastly, a dashboard developed on the MS Excel software was used for showing what a decision support platform with the algorithm developed on this work can look like, and how it can interact with the end-user, as shown on Figure 4. It is the first prototype for the development of a full platform, capable of giving information on any battery evaluated against any vehicle, the concept of "BatteryFit".

Figure 4. The BatteryFit Prototype.

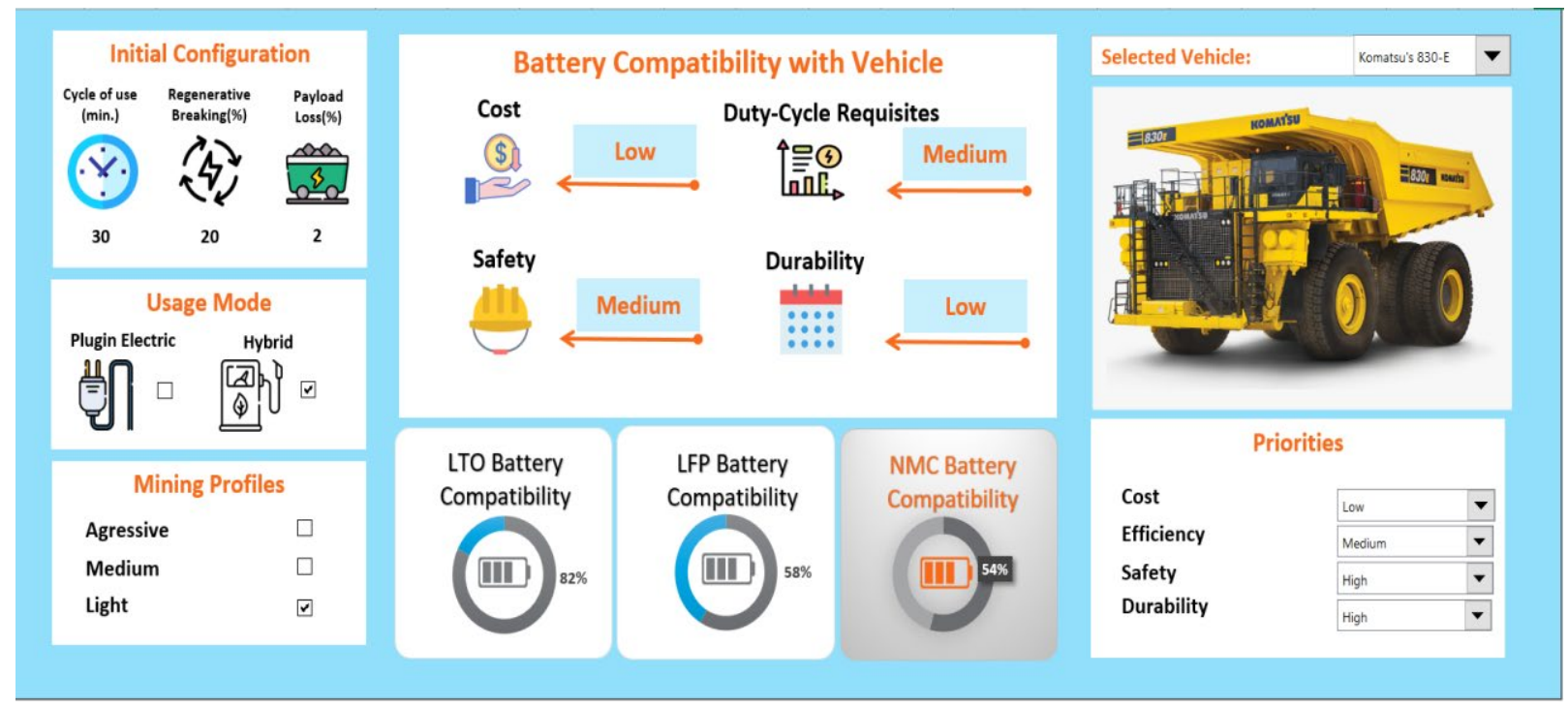

Source: Elaborated by the authors.

\section{CONCLUSION}

This work described the development of an innovative decision-making platform, not yet found in the world. With the analysis implemented on its algorithms, 
it is possible to verify that, for any of the other two technologies chosen to perform better than the LTO battery, it would have to perform at least $20 \%$ better than LTO at one of these 5 requisites, while having equal performance on all the others. This in a very unrealistic scenario, since LTO is known to be much safer than any other Lithiumion chemistry, which automatically hinders the charge and accident security requisites for the other technologies in comparison. Therefore, it can be assumed that the WASPAS method is selecting the most suitable technology from the options, with the given data.

The final analysis also proves that the methodology implemented can be an interesting tool evaluate the performance of different battery technologies on different situations. Once the data is gathered, it is quite simple to verify the possible differences in relative performance with data variations, making a fast and efficient preliminary analysis. Seen all that was presented, the created platform is successfully able to compare the data of different batteries chemistry and find out a suitable implementation on an electrification process with a given rating for each of its requisites.

\section{Acknowledgments}

The authors would like to thank to Dr. Alexandre P. Alves da Silva, to the Imperial College London Consultants, in special to Dr. Pablo Brito-Parada, who directly helped in the selection process of the MCDM method. To SENAI CIMATEC, in special to Dr. Rodrigo Santiago Coelho and Dra. Lílian Lefol Nani Guarieiro for the assistance provided, mentoring, and directing this work, to the open innovation company The Bakery, and also all other participants on the MINE program, where all the creation of this work took place, and without which this idea could not have be developed.

\section{REFERENCES}

${ }^{1}$ Martinez-Laserna, E. Battery second life: Hype, hope or reality? A critical review of the state of the art. Renewable and Sustainable Energy Reviews, v. 93, p. 701-718, 2018.

${ }^{2}$ Kingsley-Hughes, Adrian. Apple locking down iPhone batteries. ZDNet, 8 Aug. 2019. Available at: < https://www.zdnet.com/article/apple-locking-down-iphone-batteries/ > . Access on: 30 July 2020.

${ }^{3}$ HARPER, Gavin et al. Recycling lithium-ion batteries from electric vehicles. Nature, v. 575 , n. 7781 , p. 75-86, 2019.

${ }^{4}$ WENTKER, Marc; GREENWOOD, Matthew; LEKER, Jens. A bottom-up approach to lithium-ion battery cost modeling with a focus on cathode active materials. Energies, v. 12, n. 3, p. 504, 2019. 
${ }^{5}$ KANE, Mark. Volkswagen: ID.3 Battery Pack in Brief. Inside EVs, 10 Dec. 2019. Available at: < https://insideevs.com/news/387078/volkswagen-id3-battery-pack-inbrief/ >. Access on: 28 Jul. 2020.

${ }^{6}$ ENERGYSKEPTIC. Hybrid Electric Trucks are Very Different from HEV Cars. Peak Energy \& Resources, Climate Change, and the Preservation of Knowledge, 7 Jun. 2016. Available at: < http://energyskeptic.com/2016/hybrid-electric-trucks-are-verydifferent-from-hev-cars/ >. Access on: 28 Jul. 2020.

${ }^{7}$ SALITRA, Gregory et al. High-performance cells containing lithium metal anodes, LiNi0. 6Co0. 2Mn0. $2 \mathrm{O} 2$ (NCM 622) cathodes, and fluoroethylene carbonate-based electrolyte solution with practical loading. ACS applied materials \& interfaces, v. 10, n. 23, p. 19773-19782, 2018.

${ }^{8}$ BECKER, Dina et al. Surface modification of Ni-rich LiNiO. 8Co0. $1 \mathrm{Mn} 0.1 \mathrm{O} 2$ cathode material by tungsten oxide coating for improved electrochemical performance in lithium-ion batteries. ACS applied materials \& interfaces, v. 11, n. 20, p. 1840418414, 2019. 